\title{
Arosenius Translated
}

\section{Digitisation as a Rephrasing of Meaning}

\author{
JONATHAN WESTIN
}

\begin{abstract}
To analyse and discuss the procedures through which a digital copy is brought into being as a representation of the physical original, this study offers an in-depth exploration of a single digitisation effort, that of the Ivar Arosenius Archive. Using Actor-Network Theory as a theoretical framework, this article argues that to digitise is to translate, a work that demands expert knowledge in a series of disciplines such as information science, image processing, archiving and conservation. The translation functions to rephrase the archival material with the purpose of making it mobile and conform to those protocols that define something as being digital, all while enrolling associations which strengthens it as a digital original. However, through this process, the multi-sensory archive is reduced to an ocularcentric archive, potentially losing meaning.
\end{abstract}

Keywords: Digitisation, Archive, Ivar Arosenius, multi-sensory, participant observation, translate

On 8 May 2014 at 9.43 , as the studio lights were slowly warming up, the first document from the personal archive of Swedish painter and writer Ivar Arosenius was placed on a dark cloth beneath a Nikon d800e camera suspended on a stand. Over the next few months, 2,947 high-resolution TIFF files were produced from the archive material in the small photo studio at the Humanities Library and the digitisation division's locales at the Social Sciences Library in Gothenburg. The TIFF files were accompanied by a copy converted to JPEG, resulting in a digital archive containing 68,850 megabytes of data divided into 93 collections each summarised by a PDF.
The digitisation effort, accompanied by two more at the National Museum in Stockholm and the Gothenburg Museum of Art, where part of a three-year endeavour to digitise the art, documents, and artefacts pertaining to the Swedish artist Ivar Arosenius and make this diverse material available through a digital archive.

\section{INTRODUCTION}

To digitise and make available their collections have for nearly two decades been part of the work description of memory institutions such as archives, museums, and libraries (as 
evidenced by Astle \& Muir 2002). Still, it is a process not widely understood and is by many regarded as an incomprehensible procedure (Björk 2015:4). While "to digitise" is defined as the act of converting analogue media into a digital form (Oxford classical dictionary), thus "transferring materials (print sources, photographs, slides and $3 \mathrm{D}$ objects) in a variety of environments into a format that can be viewed in [a] digital environment" (Cakmak \& Yilmaz 2012), there is also an implicit understanding that certain protocols are followed. When members of the public take photographs of artefacts and documents in museums and archives and disseminate these through social media, this effort is seldom referred to as a digitisation process. Hence, there exists a difference between taking a digital photograph of something and the act performed by memory institutions when these are professionally producing digital originals through digitisation. Yet, while both the material and the immaterial aspects of an artefact constitute difficult problems in any effort of creating a faithful representation and each parameter in the process requires intellectual and critical choices (Dahlström 2010), digitisation is often treated by memory institutions as a straight forward contentmining process where the persons, protocols, processes, and technology involved serve as neutral intermediaries rather than mediators (Björk 2015:3).

However, as the layer of meaning inherited in the interplay between content and format deepens, with text on paper on one end of the spectrum and ephemeral phenomena on the other end, the impact of these mediators becomes more pronounced as the digitisation can only capture a subset of the original. This is problematic as digitisation not only constitutes an avatar or entry point to a physical object, but a placeholder often substituting the original as the broad digitisation effort made by memory institutions is an increasing consultation of secondary sources - digitisations of the primary sources (van Lit 2020). This is a development which puts pressure on what aspects and properties of the artefacts we preserve through both new and old media.

As Derrida notes, archives are not created to serve the past, but instead the future (1995). Digitisation, therefore, as a concept, must be explored as a process that transforms our future understanding of an artefact. Of interest for such an exploration are the following questions that starts the investigations in this paper: What constitutes and sets apart the professional act of digitisation, and what characteristics of an artefact are digitised?

To investigate these questions, and define digitization as a process rather than a documentation technology, this paper offers an in-depth description of the interactions involved in a single digitisation effort, that of the Ivar Arosenius Archive at the Gothenburg University Library. While the digitisation process spanned five years as the metadata describing the content of the digital files produced were being refined as part of an initiative to create a web portal for the digital material (https://aroseniusarkivet.dh.gu.se), this study limits itself to the distinct effort taking place while the originals were still being handled. By positioning the digitisation as both a documentation and a conservation effort, a process through which the material of the archive is to be represented as a way to safe-guard and communicate the information it possesses, we must not only recognise the inherent limitations of the digital media the material is represented through, and in what way those involved shape the process, but 
also the limitations of the physical archive and its individual documents and how these limitations have shaped other values around them.

\section{THEORETICAL FRAMEWORK AND METHODOLOGY}

This study analyses and discusses material collected during a participant observation study performed in the spring and autumn of 2014 and 2015 at the two sites where the documents of the Ivar Arosenius Archive were being digitised in Gothenburg, Sweden; The main locales of The University Library's digitisation division at the Social Sciences Library, and the photo studio in the Humanities Library. In mapping the interaction between the persons, technologies, and protocols involved in the digitisation process, and with a grounded theory approach (see Glaser \& Strauss 1967), this study makes use of ActorNetwork Theory (ANT). Through ANT, the persons, technologies, and protocols studied in the digitisation effort are put on a more equal footing as actors in a network of dependencies. By following individual actors and how these associate themselves with other actors, both present and far away, ANT maps out how a network is created that allows for a certain action to take place (see Latour 1992, 1993, 1994, and 2005). Assembled and combined into a whole that is constantly challenged and confirmed through negotiations, this network solidifies itself by capitalising on the actors brought into association (Harman 2009:19). While ANT is closer to metaphysics than a method or theory, by applying its focus on dependencies and associations between actors in the processes observed, it informs the methodology in great detail. Furthermore, with its roots in the sociology of scientific knowledge and technological studies and through the associated concepts of enrolment, inscription, and translation, ANT contains the vocabulary to analyse how humans and technology interact in a digitisation process.

Enrolment is the process through which actors are brought in to amass support for a cause and create a momentum (Latour 2005; Harman 2009:19). Through enrolment of materiality and non-human actors, constellations become durable and stabilise a common position. Associations through enrolment are not always logical and often fall apart when examined closely. However, when strong, they function as an equal sign between two or more disparate concepts. Through the lens of ANT, a digitisation can be described as a process that results in an inscription, a visual representation that substitutes a more complex and multidimensional substance (Latour \& Woolgar 1979:63). Hence, rather than the process itself, or the physical document digitised, it is the inscription that functions as a stepping-stone for other processes and actors (Latour \& Woolgar 1979:66). As such, an inscription is both a product and a means of productivity as the practice embodies a transformative dimension where a translation occurs. A translation is a process where the artefact is linked to another actor and is in the process mediated. Every time an actor links with another actor, a translation occurs negating any unmediated contact as the translation process mediates goal, scope and result (Callon 1986; Gunn 2009:3; Westin 2015).

Hence, a translation is not neutral, since it is coloured by contact, expression and interpretation. The inscription that the translation results in is no longer the product of a single actor, but a hybrid created from the silent negotiation with all actors in the network, even those not physically present. These actors 
could be the physical hardware necessary to carry out the digitisation, the software and licenses shaping the workflow, the persons involved, and the protocols followed.

By tracing the relations between the heterogeneous elements that compose the network, and without making a priori claims about the form of the relational configurations or formations, this article strives to gain an understanding for the temporal durability of a network that allows the physical documents in the archive to be translated into a digital archive. This is of interest as to translate is also to displace (Callon 1986), a process where negotiated representations take centre stage.

As a method, participant observation fits into the general category of qualitative research and provides an advantage to more traditional data collection such as passive observation, interviews, and literature studies, as it allows not only for the obtaining of data the researcher did not intend to look for, but it also enhances the quality of the interpretation of the collected data due to providing cognitive understanding of the processes involved (see DeWalt \& DeWalt 2011:10). Though not having a formal role in the digitisation work other than as an observing researcher, I was invited to do practical work alongside the technicians in the photo studio and follow their directions in lighting the material, calibrating the equipment and operating both scanners and camera. As I have had formal training in digital documentation processes and prior experiences with the employed technologies to draw upon, it allowed me to take note of and ask questions about the reasoning behind particular settings and procedures while operating the equipment. In addition to participant observation, several both formal and informal in-depth interviews were carried out in 2014, 2015, and 2016 with the members of the digitisation team (informants 1-3), the university library (informant 4), and the Swedish Literature Bank (informants 5 and 6). ${ }^{1}$

\section{The Ivar Arosenius Archive And the ACTORS INVOLVED}

Ivar Arosenius was a Swedish painter and writer, whose main body of work was produced during the three years that led up to his untimely death in early 1909 , only 30 years of age and within months of his big breakthrough (Asplund 1928:V). During the subsequent years and decades, his substantial production earned him recognition posthumously both nationally and internationally, and today he is viewed as one of the most renowned Swedish artists (Fredlund 2009; Westin and Claésson 2017).

In the care of Gothenburg University library's Manuscript collection, the Ivar Arosenius Archive consists of letters, inventories, legal documents, photographs, newspaper clippings, notebooks and exhibition catalogues. Built on the foundation of a deposition of manuscripts obtained from the Royal Society of Arts and Sciences in Gothenburg in 2001 (Informant 4), the Ivar Arosenius Archive at the university library in Gothenburg has over the years swelled both through additional donations and accessions, and through the work of Ivar Arosenius' granddaughter, Astrid ConstantineTorstensson. The archive encompasses both originals and copies dating from 1896 to 2012. In addition to the many photographs, letters and legal documents pertaining to Ivar and his closest relatives - Ida/Eva Arosenius-Dich (née Adler), Eva Arosenius-Constantine and Astrid Constantine-Torstensson - the archive also includes an accumulation of exhibition catalogues and newspaper clippings collected by Ivar's brother-in-law, Nils Adler (Informant 3). 


\section{JONATHAN WESTIN}

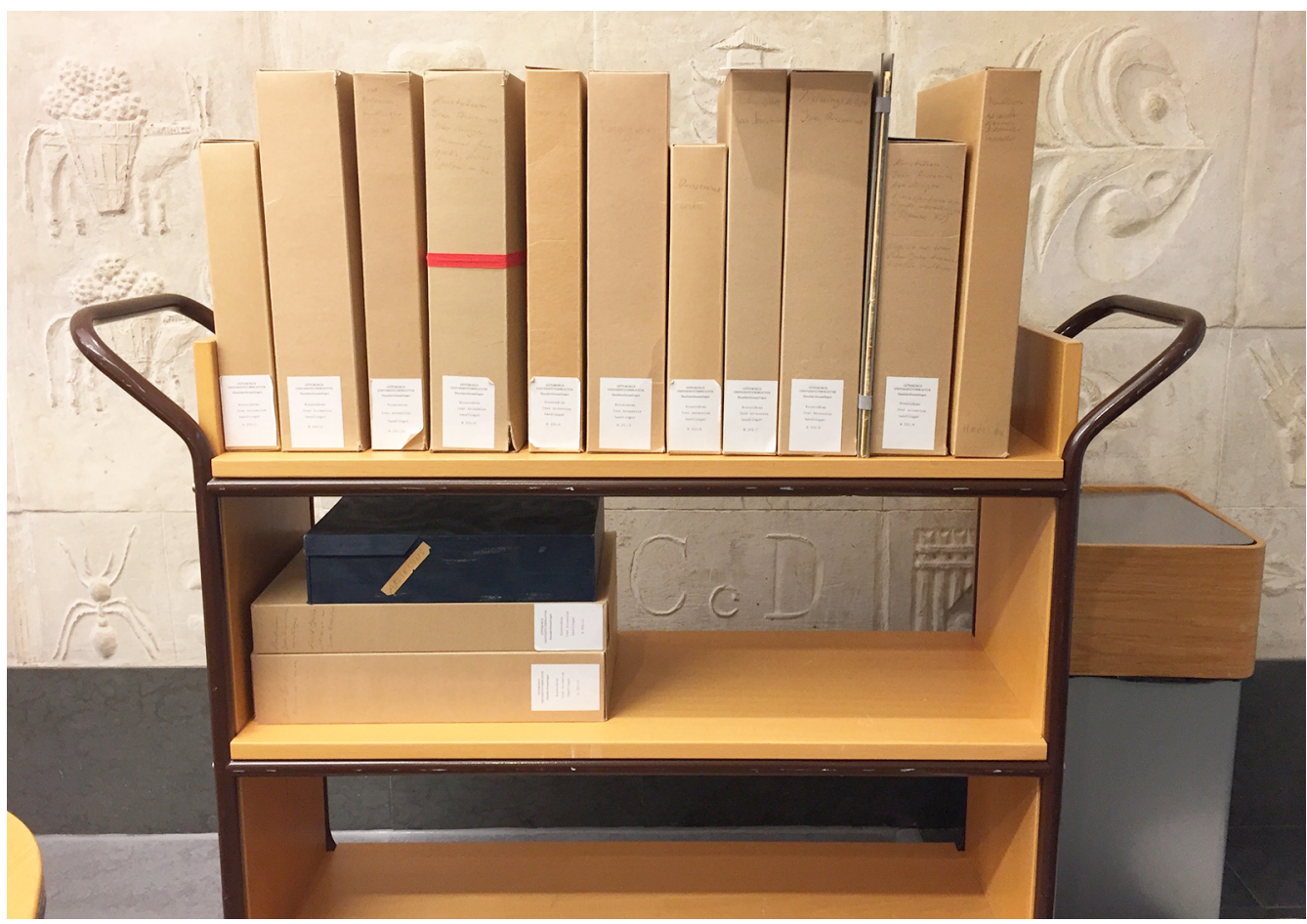

Fig. 1. Trolley carrying the capsules from the manuscript vault to the photo studio. Photo: author.

Held in fourteen capsules in the manuscript vault at the library, interaction with the documents of the archive demands a formal request to be made, followed by a scheduled appointment. All except one of the capsules that make up the Ivar Arosenius Archive are uniform in appearance; tan coloured cardboard boxes 31 by $22 \mathrm{~cm}$, and $10 \mathrm{~cm}$ deep (fig. 1). Each capsule represents a context, but with a nested logic; while one context could be "photographs", or perhaps "letters", this does not imply that all photographs or letters of the archive are within a particular capsule, but rather, for instance, all photographs from a certain donation, or all letters on a certain subject.
The digitisation was commissioned by the Gothenburg University Library and the Swedish Literature Bank, a co-operation between the Swedish Academy, the Royal Library of Sweden, the Royal Swedish Academy of Letters, History and Antiquities, the Language Bank of the University of Gothenburg, the Swedish Society for Belles Letters, and the Society of Swedish Literature in Finland (informants 5 and 6). The aim with the digitisation was to decrease the wear on the originals, and explore opportunities for collaboration with the Gothenburg Museum of Art and the Swedish National Museum in Stockholm, both of whom have digitised substantial parts of their Ivar Arosenius collections. 
The University Library employs thirty persons working on digital resources at a division called Digit, a cluster of employees, protocols, licenses, and machines that is divided into four distinct teams handling e-resources, publishing, development, and digitisation. Every digitisation work starts with the creation of a project in D-Flow, the custom server backend written in Ruby for the digitisation team. When handling less sensitive documents, the pages are loaded in the paper feeder of a Canon ImageFormula. Each page is then scanned through the software ScanGate by Triventus in $300 \mathrm{dpi}$. Metadata is added manually at this first station by one of the employees at the digitisation team. This metadata does not describe the content of the material or the physical condition of the original, but instead collects information about the specific context of the physical page in relation to the publication it is part of; if it is on the left or on the right side of a spread or if the page contains an index.

ScanGate uses Optical Character Recognition (OCR) to straighten all scanned pages, but does at this stage not add any text information to the file. The OCR functionality is part of the software, but requires an annual license fee to be paid to ABBYY, the Munich-based company developing the server-residing software (Informant 1). After being loaded with metadata and straightened, the digital pages are brought into a second station where they are cut by a second employee to only leave the layout area and do away with any borders originating in the scanning process and subsequent adjustments. Finally, they are brought into D-Flow and are matched with the associated project. The high-resolution TIFF files produced are automatically copied and converted into JPEG-files, with the resolution intact, and turned into a PDF through the licensed ABBYY-server where added, containing measurements and relevant copyright information. The OCR data is also saved to individual ALT-XML files, one for each scanned page, that can be combined with the high-resolution files if future uses demand it.

For manual scans, the digitisation team employs either an Epson Perfection v750 Pro flatbed scanner or a Plustek A3. The former has the advantage of a recessed scanning area which allows for scanning of glass plates or thick archival documents, while the latter's edge-free construction makes it superior for scanning single pages from books. The Epson scanner is operated through the software EpsonScan, and the Plustek is handled through the free software IrfanView. For larger objects, or when the material is particularly sensitive, the team employs a Nikon d800e camera operated by CameraControl from Nikon, an application that lets the user handle the settings of the camera from a connected computer.

\section{Translating THE ARCHIVE AND ENROLLING THE ACTORS}

On 24 March 2014 at 14.30, one and a half months before the studio lights were turned on in the small photo studio at the University Library, the documents of the archive were subjected to a new vocabulary. In a planning meeting held between representatives from the University Library and the Swedish Literature Bank, guidelines for the coming digitisation work were being drawn out and discussed in consultation with Jimmy Carlsson, lead technician on the digitisation of the Ivar Arosenius Archive (Siira 2014). While then still in their tan cardboard capsules, safely locked away in the manuscript vault fifty meters and a floor away, the documents 


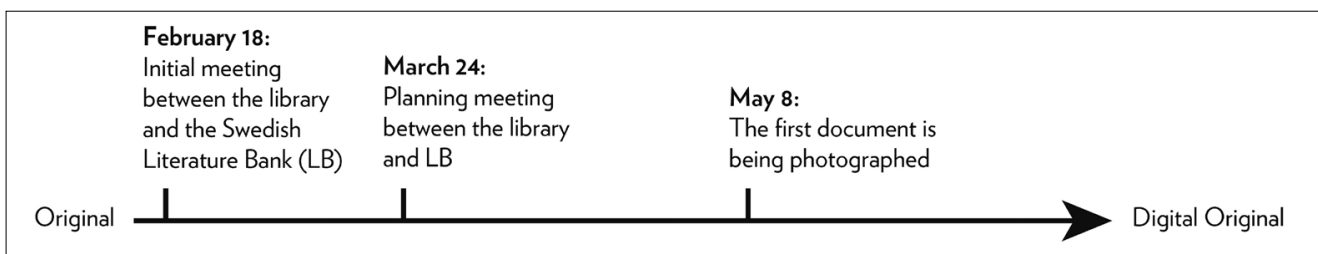

Fig. 2. The timeline for the digitisation effort.

were even so weighted and measured by the participants at the meeting, trying to gauge the needs and wants of future researchers concerning resolution and information. The documents were quantified in megabytes and gigabytes, DPI, formats, bit depth and colour spaces, all weighted against costs associated with digitising and storing the material: Is it worth the cost of storage and time to double the resolution of each scanned manuscript, to be able to trace a tremble in the hand of the writer? Will there ever be a researcher, or perhaps a technology, that could make use of information that is lost in $600 \mathrm{DPI}$ ? The discussion leads to decisions, which leads to a protocol (Siira 2014), drawn up to function as an inscription that would guide the coming months of work for Carlsson and his colleagues (fig 2).

On 8 May 2014 at 10.03, after having burned for twenty minutes the studio lights had finally gained the right temperature. Carlsson sighs saying that a planetary scanner would have cut some waiting times, and would most certainly produce a more even result. However, the time it took for the studio lights to warm up were not spent idle: the Nikon d800e was adjusted, the Plustek A3 scanner and the computer were turned on and their connection with the software was established, the windows were covered and the cardboard capsule containing the archival material was opened, its content organised on a trolley. What first had appeared as no more than a large closet filled with camera equipment had been turned into a laboratory; a controlled milieu with an even light and separate stations for specific activities.

The interdependence between the human and non-human actors become apparent in how the work process within the laboratory is structured. While only one technician is present at any given time, together with different machines and software that all brings different advantages and disadvantages to various tasks in the process, that person can put together a workflow and perform a series of actions that result in a digitisation with a particular end result that meets the standard of established protocols. Likewise, if any one of the actors involved would break or refuse to cooperate, or if there had been a clerical error when any of the software licenses were to be renewed, the workflows, timetables, processes - and, possibly, the established protocols would have to be renegotiated.

Wrapped with a thin red band it had been easy to spot the capsule we were to start with amongst the other cardboard boxes in the Manuscript Vault. In following with the digitisation plan drawn up by Carlsson after an initial meeting on February 18 between the library and the Swedish Literature Bank (informant 1), the capsule with the red band was brought to the photo studio housed in the repro division, a five-minute walk from the Manuscript Vault, rather than across town to Digit's main locales at the Social Sciences Library.

The equipment is calibrated four times 
every year, but an additional calibration is performed at the beginning of each new project. To perform a calibration, a colour stick is photographed or scanned, depending on if it is the Nikon or the Plustek being calibrated. The resulting image is then uploaded to a site where the user can compare his or her image to that of an image obtained through a calibrated scanner or camera. Following routines set up by Erik Siira, system developer at the digitisation team, Carlsson measures the image against the Metamorfoze-standard (informant 1). Up to this point the actors directly involved are many but could still be counted; Jimmy Carlsson, Erik Siira through handed down routines, the representatives from the library and the Swedish Literature Bank through the digitisation plan and the protocol detailing the extent of the digitisation, as well as D-Flow, the Plustek flatbed scanner, the Nikon D800e, the computer and the calibrated screen, IrfanView, the studio lights, the colour checkers, and the protocols established by digit for various material categories. In addition to these, we have the actors standing ready to step in when the material or workflows demands it; the colleagues at Digit if Jimmy Carlsson would be unavailable, the Canon ImageFormula and the Epson Perfection flatbed scanners, Scangate by Triventus, the OCR license from ABBYY, and the ScanRobot. However, by enrolling the Metamorfoze-standard this group expands significantly.

The Metamorfoze Preservation Imaging Guidelines were developed in the Netherlands by the National Library of the Netherlands and the National Archives on an initiative by the Ministry of Education, Culture and Science (van Dormolen 2012). In addition to the instigators of the standard, there are many researchers who have perfected it during the years and whose protocols and recommendations we now follow just as faithfully as we follow the protocols drawn out at the planning meeting and those procedures our Plustek scanner and Nikon Camera dictate. The guidelines are intended for the digitisation of two-dimensional materials, including manuscripts, paper archives, texts, paintings and photographs. As such, the standard is meant to inform the creation of a preservation master, a first file from which all other digital derivatives may spring, and state that the "preservation masters provided in this context must be of such a quality and measurable relationship to the original, that they can in fact replace it" (van Dormolen 2012). The standard however has different tiers; for instance, the lightest level, primarily used by Digit when digitising dissertations, focuses on giving a clear and readable result rather than trying to capture the physical appearance and colour variations of the paper the text is printed on.

\section{WHAT TO TRANSLATE...}

Each document is scanned or photographed in a resolution of 600ppi, and saved into a TIFF format with LZV-compression and an RGB colour space. However, there are no protocols to follow when deciding upon if a document should be photographed using the Nikon800e or scanned with the Plustek A3 Scanner. Although it is a slightly more challenging procedure - demanding more choices and corrections for each document - the technician can choose to photograph a document instead of scanning it: the camera lends the illusion of depth to the digital file and brings forth the texture of the document, while the scanner creates a flatter more even result where all shadows are negated by the uniform light (Informant 3). The technician can thus, 


\section{JONATHAN WESTIN}

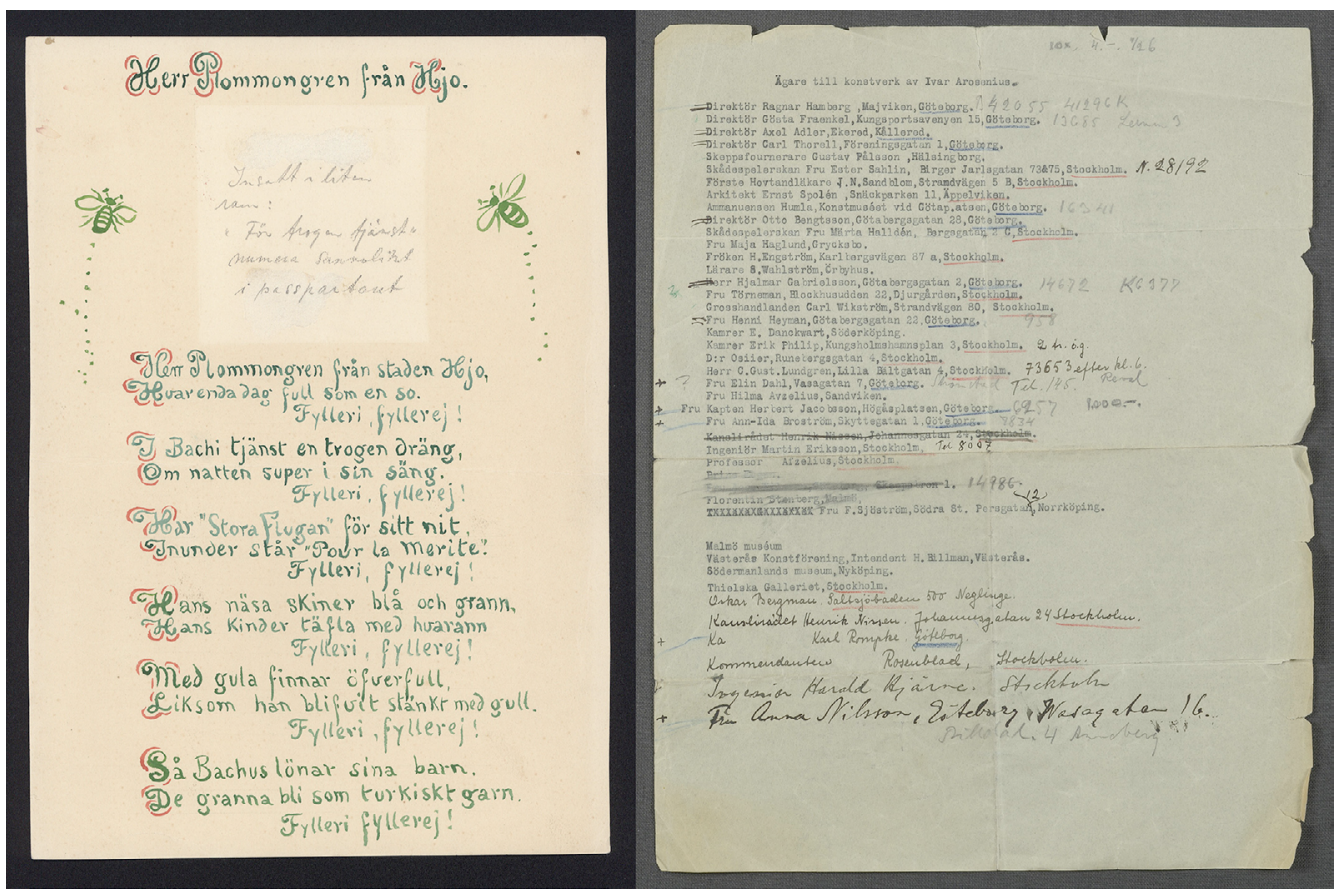

Fig. 3. A comparison between scanned page (left) and photographed page (right). Photo: author.

by choosing the technology through which they align themself, translate the document into a digital copy that adheres to one of two different philosophies in regard to digitising. One includes the illusion of the shape of the page through slight shadows and in that way also the context of the document, while the other strives for neutrality and a uniform appearance (fig. 3).

\section{... AND WHAT NOT TO TRANSLATE}

The Metamorfoze standard states that "all the information visible in the original must also be visible in the preservation master; the information transfer must be complete since the original is threatened by autonomous decay and will no longer be used once it has been digitized" (van Dormolen 2012). This means that to limit oneself to following the minimum requirements of the Metamorfoze standard is to disregard the non-visual aspects of a document, or to confine the digitisation to aspects we can perceive under particular, often limited, conditions. Regardless, the standard puts this visible information in the context of being a complete information translation that negates the need of the original.

This focus on the visual is echoed in the standard protocols set up by Digit, and in the material specific protocols inscribed from the meeting between Digit, the University Library, and the Swedish Literature Bank on March 24. All the new terminology used to describe the technical aspects of the digital documents, the metadata of each file, only stores information 


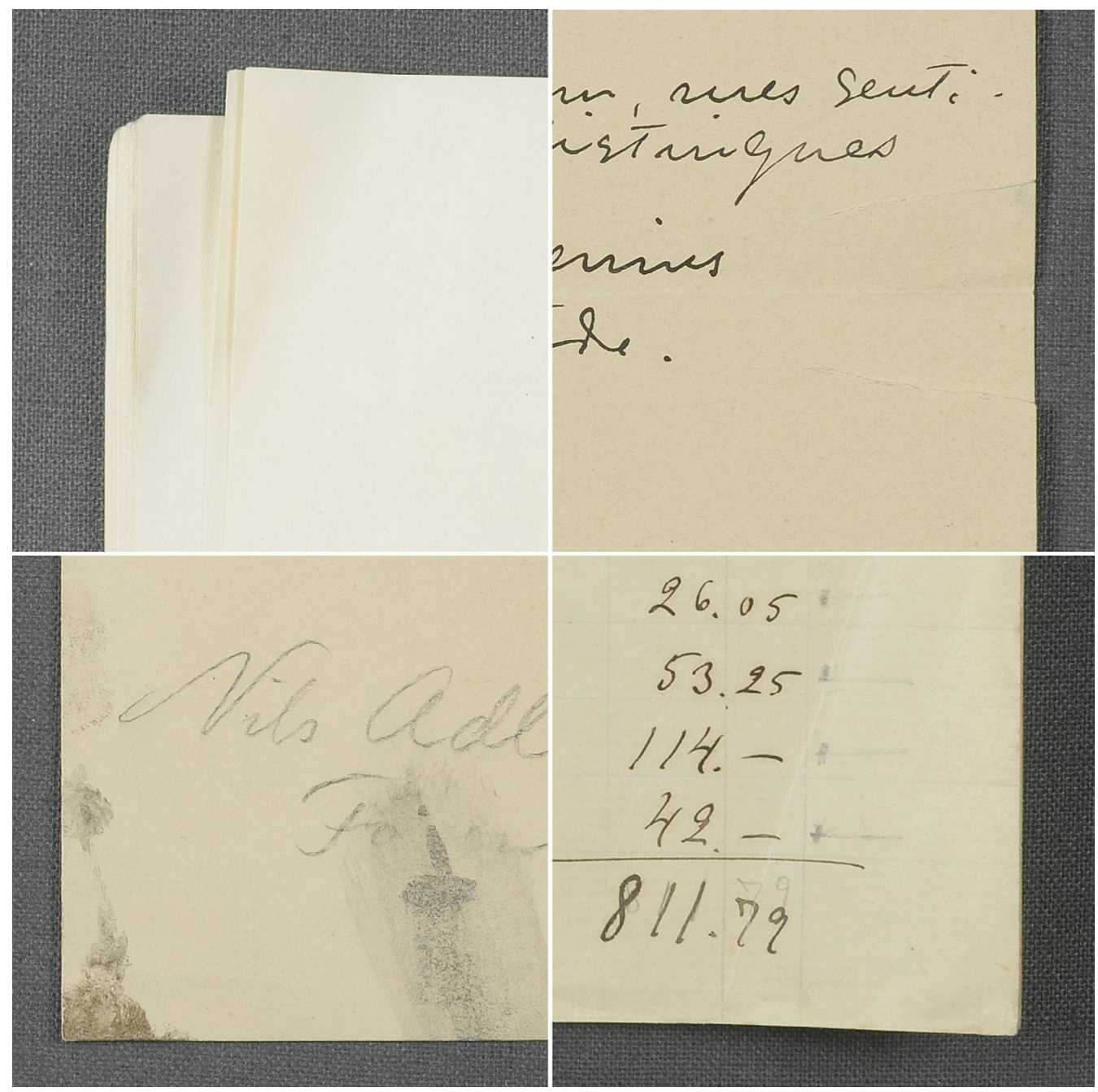

Fig. 4. Details from the digital originals displaying visual cues about the physical condition of the originals. Photo: author.

pertaining to the visible aspects of the physical document, and this is done without input from domain experts who could shed light on what aspects of the document's physicality is important to preserve as metadata. Multisensory information, such as the feel of the document, its structure and depth, are only hinted at through the capture of visual cues (fig. 4). Others, while visual in nature, such as watermarks only perceivable under the right conditions, or multispectral information in the infrared or ultraviolet spectrum, are not recorded. Finally, the smell of the document, the sound of the document when handled, 
and microorganisms, are not translated and thus never becomes part of the digital original. Hence, the handling of manuscripts as a "bidirectional contact that involves not only all five senses but also or internal capacity to interpret and communicate the holistic experience that emerges from this contact" (van Lit 2020:60f) is severally stymied by the digital original (see also Nolan 2013 and Kropf 2017).

\section{Discussion}

Derrida writes that "the technical structure of the archiving archive also determines the structure of the archivable content even in its very coming into existence and in its relationship to the future" (Derrida 1995:17). However, just as the technical structure of the archive determines the boundaries of what can be archived, the technical structure of the digitisation process determines the boundaries of our future understanding of an archived item. When approached as a process of translation rather than a documentation technology, each step of a digitisation becomes important to consider. Furthermore, as a process that connects the past with the future, these considerations must extend past the digitisation act into the archivisation practice as the latter is limited by the depth of the former. When a document or artefact is digitised, a process as often viewed as "making a backup" as a way to add value for an audience, it is detached from the context to which it was bound by its physicality. Relations between different objects, hierarchies, and groupings, absolute limitations all important for the organisation of the physical archive and values of the originals, become artificial limitations in the digital archive where objects can have several positions at once and thus several associations.
The heritage sector has seen an increasing number of ways to document, digitise, and visualise multidimensional aspects of physical artefacts and monuments using laser, structured light, and structure-from-motion (see Pierracini et al. 2001; Yastikli 2007; Latour \& Lowe 2011; Galeazzi et al. 2015; Harrison 2019; Almevik \& Westin 2020). In contrast, from the outside, a digitisation of a manuscript archive can appear almost deceitfully simple; there is a paper document that is either photographed with a digital camera or scanned to obtain a digital replica of said document. However, the procedures involved in the digitisation of the Ivar Arosenius Archive reveal a number of complexities when studied up close.

Through the lens of ANT, these processes are not only dictated by the persons directly involved, nor the persons present at the meetings, but include OCR-licenses, the protocols of the Metamorfoze standard organisation, limitations in software and hardware, established workflows, policies, documents, and budgets. Following ANT, the process can be described as a network of heterogeneous actors, both human and non-human, that come together to allow for a translation of the archive into digital form. The translation functions to rephrase the archival material with the purpose of making it mobile and conform to those protocols that define something as being digital. However, this rephrasing does not only shed away the physicality of the documents, replacing the feel of texture with nothing but the look of texture through a flattening of the dimensions of the documents, but does also introduce a whole new vocabulary that in many ways replaces the one art historians, archivists and conservators use to describe the physical manuscripts.

While this translation effort demands expert knowledge in a series of disciplines 
such as information science, image processing, archiving and conservation, it is also a process marked by considerations of aesthetics. Using the Canon d800e to photograph the documents instead of scanning them with the Epson Plustek proved to be a less efficient but richer method that brought values to the digitisation by translating immaterial aspects inherit in the physicality of the document that would otherwise have lost since these were not covered by the protocols. This change in technology not only adds perspective but widens said perspective to include the immediate context of the manuscript page. What in the protocols was seemingly a flat page is now revealed to be a three-dimensional object hinting at the affordances of the original. Hence, during a digitisation process the source document remains in a state of flexibility and can be stabilised in several ways through the digital original. Reasoning that the digital is grounded in materiality, Kreiss and Brennan argue that it is the way in which a "digitization mediates between the material and the immaterial [...] that makes digitization a unique process" (2014). While they focus on the immateriality of the digital, every artefact is multi-dimensional and multi-relational, both as a physical object and as a concept defined through its relations in society, meaning that materiality is already entwined in immateriality. Furthermore, an artefact can be described at different scales, ranging from properties of its materiality, to the object as a symbol through both its physicality and representations, to the object on a conceptual level. All archive documents are therefore products of both their material properties and their immaterial aspects, which include affectional values, associated traditions, and context - amassed through the life time of the documents, and multiplied by copies both analogue and digital.
When digitised, the visible information of the documents in the Arosenius Archive are reproduced as digital files. The information is thus separated from the context of the physical artefact that lent it authenticity and made it into an original. However, by following the workflow of Digit, standard organisations, protocols, and policies are enrolled to the digital replica. None of the machines or software, or even the employees, can by themselves digitise a single document. Just like the Canon ImageFormula needs ScanGate, and ScanGate needs a computer with a screen and an electrical grid, and these four nonhuman actors an expert handler who has gained knowledge of all the relevant settings, this group is reliant on not only protocols and policies drawn up and stored by their colleagues in the adjoining room at Digit, but they rely on the OCR-servers in Russia and the licenses that keep them connected, the caretaker transporting the manuscripts from the vault at the central library to the vault in Digit's locales at the Social Sciences Library, the list of assignments from the University Library Council and the establishing of a project code in D-Flow. The network of machines, software, experts and manuscripts are motionless without the countless actors making up the infrastructure, but when activated they work to support the digital file being created; making it less of a copy and more a digital original.

Just by utilising the Metamorfoze standard a host of associates are enrolled, including the Van Gogh Museum, Rijksmuseum in Amsterdam, Metropolitan in New York, and the City Archive of Amsterdam, that all strengthen the argument that the digital originals are "true copies" (van Dormolen 2012). They are not just bits, but authorised bits. As Latour and Lowe write, "hidden behind the common sense distinction between original 


\section{JONATHAN WESTIN}

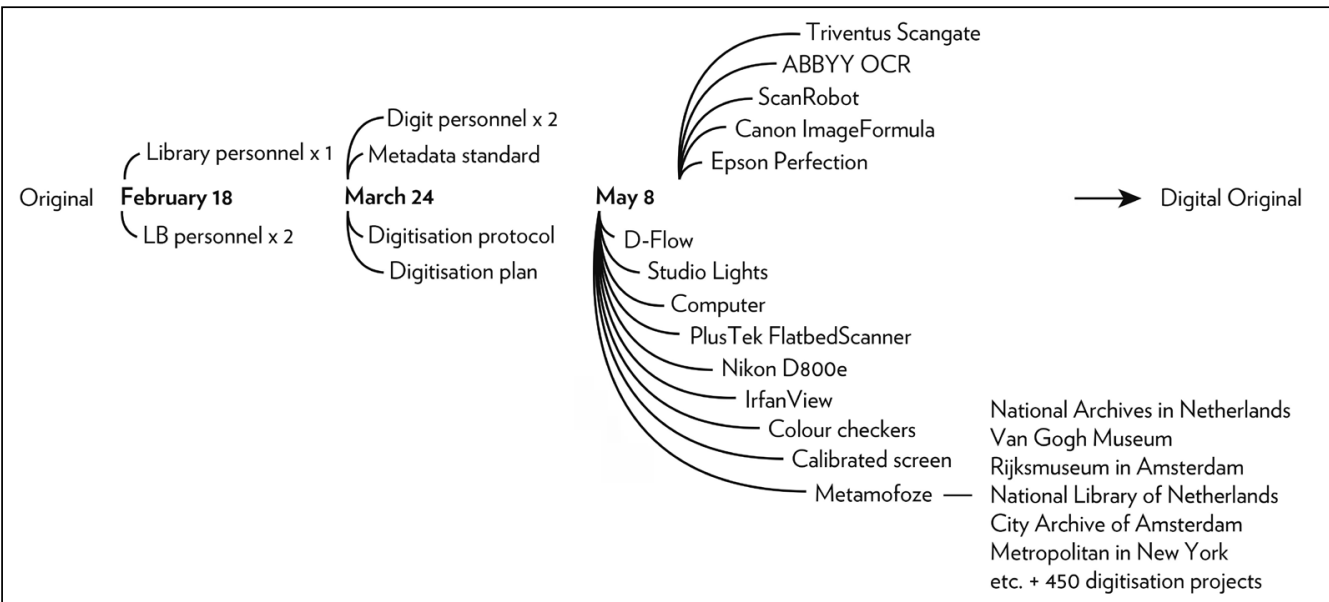

Fig. 5. The accumulated network of enrolled actors.

and mere copies, lies a totally different process that has to do with the technical equipment, the amount of care, the intensity of the search for the originality that goes from one version to the next" (Latour \& Lowe 2011:12). The original is not translated haphazardly, then it would have amounted to no more than a mere copy, but through a careful enrolment of technologies and standards. Hence, to answer the first question of this study, what constitutes the professional act of digitisation is as much about creating an argument for the solidity of the digital inscription through enrolment as it is about abandoning physical restraints. Though the digital copy lacks physicality it is not without substance (fig 5). When the documents of the Ivar Arosenius Archive are being digitised, layers upon layers of physical information are being traded for the gains in mobility a digital copy promises. The manual metadata assigned each document in the digital archivisation process mimics in much the metadata recorded in the physical Arosenius Archive and includes date, technique, measurements, collection, category, sub category, places, persons, and tags. With the exception of "collection", which describes what memory institution the physical document is stored in, all these are limited to data describing the visual characteristics of the document captured by the translation into digital form. While this could be argued to be enough in a context where the physical artefact is present, it serves to emphasise both the digital representations lack of depth and the need for a critical approach to how metadata can be used to narrate the artefact and record more than visual aspects (see Odumosu 2020:299).

While an archive is an assemblage of documents and artefacts (Harrison 2013), each document is also an archive of less curated, and thus less subjective, information. However, digital replicas lack unprocessed information, thereby turning mute when moving past the visual aspects of the surface pixels (Forte 2000). While seldom considered in a digitisation effort, those non-visual aspects of an artefact not communicated through its external appearance, such as how it feels to the touch, is an integral part of it not being 
translated. Likewise, even visual aspects of its physical manifestation, such as how light is reflected at different angles that might offer up clues in regards to how it has been approached, perceived, and used, are rendered invalid by the neutral lights of the digitization process. When preserving the memory of an artefact through digitisation, by not acknowledging the particulars of a physical format one negates many of the cultural connotations connected to it (Lemmonier 1993; Westin 2013; van Lit 2020). Since cultural values are tied to both usage and the branching of that usage, the digital document risks being considered no more than a shallow snapshot of documentation rather than documentation in its own right. Hence, in regards to the question of what characteristics of an artefact are digitised, by itself the digitisation of the Arosenius Archive captures only those aspects of the originals possible to gather if they had been on display behind glass; manuscripts in isolation and devoid of context, to be looked at from a distance in an even light.

As we have seen, the process of translation involves the enrolment of an intricate system of actors and associations. This enrolment allows the digital translation to become official, an inscription which is an entity unto itself and that can be referenced and archived. However, as an inscription or placeholder for the original, all intermediary steps of its production, and the information that has been shed through those steps, risk being forgotten (Latour \& Woolger 1979:63). Hence, the ocularcentric digital representations of the archival material solidify the visual qualities of a document as not only more important than other qualities, thus amounting to what Rose describes in the context of representation as 'made meanings' (Rose 2006:2), but the only qualities of the document. This is emphasised by the Metamorfoze standard when it is describing this ocularcentric information transfer as complete (see van Dormolen 2012). The physical archive, already subjected to limitations, choices, random circumstances, and politics (see Stevenson 2013:160ff), is in these instances curated anew through the very process of digitisation. According to Rose, archives cannot simply be treated as "transparent windows onto source materials. Archives work in quite particular ways that have effects on what is stored within them, and on those who use them" (Rose 2012:228). Every item in an archive has gone through a process of selection, which means a conscious decision has been made concerning what parts of a greater material availability were worth keeping and what parts were not (Herlitz \& Westin 2018). This creation of meaning does not end with the archivist or the digitisation process, as each user generates a new story from the material (Breakell 2008: paragraph 26).

Studies of the digital archival material, and future opportunities for activation in new contexts that might help bridge the present and the past to advance our knowledge, is thus limited to the ocularcentric "made meaning" of the document produced by the digitisation process. Hence, when through the act of digitisation we produce official inscriptions of artefacts made to replace them as objects of reference, steps should be taken to reflect on their physical and non-visual qualities as carriers of meaning threatened by this process of translation.

\section{Notes}

1. Informants: 1 Jimmy Carlsson, 2 Lennart Stark, 3 Grim Dellsén, 4 Anders Larsson, 5 Dick Claesson, 6 Mats Malm 


\section{LITERATURE}

Almevik, Gunnar \& Jonathan Westin 2020. "Entering Hemse. Enacting the assemblage of a 12thCentury Gotlandic stave church." "For My Descendants and Myself, a Nice and Pleasant Abode" - Agency, Micro-history and Built Environment. Buildings in Society International BISI III, Stockholm 2017. Oxford: Archaeopress, 13-28.

Astle, Peter J. \& Adrienne Muir 2002. “Digitization and preservation in Public Libraries and Archives." Journal of Librarianship and Information Science 34, 67-79.

Baron, Jaimie 2014. The Archive Effect: Found Footage and the Audiovisual Experience of History. London: Routledge.

Björk, Lars 2015. How Reproductive Is a Reproduction? Digital Transmission of Text-Based Documents. Borås: University of Borås.

Breakell, Sue 2018. "Perspectives. Negotiating the archive." Tate Papers, Issue 9, April 2008. http:// www.tate.org.uk/research/publications/tatepapers/09/perspectives-negotiating-the-archive [Accessed 2020-08-09]

Çakmak, Tolga \& Bülent Yılmaz 2012. “Overview of the digitization policies in cultural memory institutions in turkey." In Serap Kurbanoğlu, Umut Al, Pyllis Lepon Erdoğan, Yasar Tonta \& Nazan Uçak (eds). E-Science and Information Management. IMCW 2012. Communications in Computer and Information Science, vol 317. Berlin: Springer, 49-91.

Callon, Michel 1986. "Some elements of a sociology of translation: domestication of the scallops and the fishermen of St Brieuc Bay." In John Law (ed). Power, Action and Belief: a New Sociology of Knowledge? London: Routledge Kegan \& Paul, 196-223.

Dahlström, Mats 2010. “Critical editing and critical digitisation." In Wido van Peursen, Ernst Thoutenhoofd \& Adriaan van der Weel (eds.) Text
Comparison and Digital Creativity, Leiden: Brill, 77-97.

Derrida, Jacques 1995. Archive Fever. A Freudian Impression. London: The University of Chicago Press.

DeWalt, Kathleen Musante \& Billie DeWalt 2011. Participant observation: A guide for fieldworkers. Plymouth: AltaMira Press.

van Dormolen, Hans 2012. "Metamorfoze preservation imaging guidelines." https://www.metamorfoze. $\mathrm{nl} /$ sites/default/files/publicatie_documenten/ Metamorfoze_Preservation_Imaging Guidelines_1.0.pdf [Accessed 2021-03-24]

Forte, Maurizio 2000. "The invisible landscape: behind the GIS and towards the virtual archeology." Harvard GIS Colloquium Series.

Galeazzi, Fabrizio, Paula Di Giuseppantonio Di Franco \& Justin Matthews 2015. “Comparing $2 \mathrm{D}$ pictures with $3 \mathrm{D}$ replicas for the digital preservation and analysis of tangible heritage." Museum Management and Curatorship 30:5, 462-483.

Glaser, Barney \& Anselm Strauss 1967. The Discovery of grounded theory. London: AldineTransaction.

Harman, Graham 2009. Prince of Networks: Bruno Latour and Metaphysics. Melbourne: Re.press.

Harrison, Laura 2019. "A roadmap to applied digital heritage: introduction to the special issue on digital heritage technologies, Applications and Impacts". Studies in Digital Heritage, 3(1), 40-45.

Harrison, Rodney 2013. "Reassembling Ethnographic Museum Collections”. In Rodney Harrison, Sarah Byrne \& Anne Clarke (eds). Reassembling the Collection, Santa Fe: SAR Press, 3-35.

Herlitz, Alexandra \& Jonathan Westin 2018. "Assembling Arosenius - staging a digital archive". Museum Management and Curatorship 33:5, 447-466.

Kreiss, Daniel \& Scott Brennan 2014. "Digitalization and digitization." http://culturedigitally. org/2014/09/digitalization-and-digitization/ [Accessed 2020-09-01]

Kropf, Ewyn 2017. "Will that surrogate do? 
Reflections on material manuscript literacy in the digital environment from Islamic manuscripts at the University of Michigan Library." Manuscript Studies 1:1, 52-70

Latour, Bruno 1992. "Where are the missing masses? The sociology of a few mundane artifacts." In: Wiebe Bijker and John Law (eds.) Shaping Technology/Building Society: Studies in Sociotechnical Change. Cambridge: MIT Press, 225-258.

Latour, Bruno 1993. "Ethnography of a 'high-tech case': about Aramis." In Pierre Lemmonier (ed.) Technological Choices. Transformation in Material Cultures Since the Neolithic. London: Routledge.

Latour, Bruno 1994. "On technical mediation philosophy, sociology, genealogy." Common knowledge (3:2), 2004: 29-64.

Latour, Bruno 2005. Reassembling the Social. Oxford: Oxford University Press.

Latour, Bruno \& Steve Woolgar 1979. Laboratory Life: The Construction of Scientific Facts. Princeton: Princeton university press.

Latour, Bruno \& Adam Lowe 2011. “The migration of the aura, or how to explore the original Through its fac similes." Switching Codes Thinking Through Digital Technology in the Humanities and the Arts. Chicago: University of Chicago Press, 275-297.

Lemonnier, Pierre 1993. "Introduction”. In Pierre Lemmonier (ed.). Technological Choices: Transformation in Material Cultures Since the Neolithic. London: Routledge, 1-35.

van Lit, Cornelis 2020. Among Digitized Manuscripts. Philology, Codicology, Paleography in a Digital World. Brill 2020.

Nolan, Maura 2013. "Medieval habit, modern sensation: reading manuscripts in the digital age." The Chaucer Review 47, no. 4 (2013), 465-476

Odumosu, Temi 2020. "The crying child. On colonial archives, digitization, and ethics of care in the cultural commons." Current Anthropology 61:22, 289-302.
Pieraccini, Massimiliano, Gabriele Guidi \& Carlo Atzeni 2001. "3D digitizing of cultural heritage." Journal of Cultural Heritage, 2:1, 63-70.

Rose, Gillian 2006. Visual Methodologies: An Introduction to the Interpretation of Visual Materials. London: Sage Publications.

Rose, Gillian 2012. Visual Methodologies: An Introduction to Researching with Visual Materials. 3rd ed. London: Sage Publications.

Siira, Erik 2014. Avstämningsmöte Litteraturbanken. Unpublished protocol. 2014-02-18.

Stevenson, Jane 2013. "'I can never find anything among the piles of old paper and general rubbish. Edward Burra and his archive." In Judy Vaknin, Karyn Stuckey \& Victoria Lane (eds). All This Stuff! Archiving the Artist. Faringdon: Libri, 157-170.

Westin, Jonathan 2013. "Loss of culture: new media forms and the translation from analogue to digital books." Convergence 19(2), 129-140.

Westin, Jonathan 2015. "Inking a past; visualization as a shedding of uncertainty." Visual Anthropology Review 30:2, 139-150.

Westin, Jonathan \& Dick Claésson 2017. "The painter is absent: Ivar Arosenius and the site-specific archaeo-archival reconstruction of the ghost of a home". Bebyggelsehistorisk tidskrift 73, 116-129.

Yastikli, Naci 2017. "Documentation of cultural heritage using digital photogrammetry and laser scanning". Journal of Cultural Heritage, 8:4, 423-427.

Jonathan Westin, Docent, Research Coordinator at Centre for Digital Humanities jonathan.westin@lir.gu.se

\section{Centre for Digital Humanities}

Box 100

SE-405 30 Gothenburg, Sweden https://www.gu.se/omuniversitetet/ personal/? userId=xwejon 